Bond University

Research Repository

\title{
Long-term effects of school barefoot running program on sprinting biomechanics in children: A case-control study
}

Mizushima, Jun; Keogh, Justin W.L.; Maeda, Kei; Shibata, Atsushi; Kaneko, Jun; OhyamaByun, Keigo; Ogata, Mitsugi

Published in:

Gait and Posture

DOI:

10.1016/j.gaitpost.2020.09.026

Licence:

CC BY-NC-ND

Link to output in Bond University research repository.

Recommended citation(APA):

Mizushima, J., Keogh, J. W. L., Maeda, K., Shibata, A., Kaneko, J., Ohyama-Byun, K., \& Ogata, M. (2021).

Long-term effects of school barefoot running program on sprinting biomechanics in children: A case-control study. Gait and Posture, 83, 9-14. https://doi.org/10.1016/j.gaitpost.2020.09.026

\section{General rights}

Copyright and moral rights for the publications made accessible in the public portal are retained by the authors and/or other copyright owners and it is a condition of accessing publications that users recognise and abide by the legal requirements associated with these rights.

For more information, or if you believe that this document breaches copyright, please contact the Bond University research repository coordinator 


\section{Long-term Effects of School Barefoot Running Program on Sprinting Biomechanics in Children: a Case-Control Study}

\section{Highlights}

- Habitual barefoot running children had shorter contact times and longer flight times.

- Habitual barefoot running children used a more anterior FSP in shod sprinting.

- Habitual barefoot running children jumped higher with shorter contact time.

- Longitudinal research is required to confirm the optimal dosage of barefoot running. 
Title page

\section{Long-term Effects of School Barefoot Running Program on Sprinting Biomechanics in Children: a Case-Control Study}

Jun Mizushima $^{1}$, Justin W.L. Keogh ${ }^{2,3,4,5}$, Kei Maeda ${ }^{6}$, Atsushi Shibata ${ }^{1}$, Jun Kaneko ${ }^{7}$, Keigo Ohyama-Byun $^{8}$ and Mitsugi Ogata ${ }^{8}$

${ }^{1}$ Graduate School of Comprehensive Human Sciences, University of Tsukuba, Ibaraki, Japan

${ }^{2}$ Faculty of Health Sciences and Medicine, Bond University, Gold Coast, Australia

${ }^{3}$ Sports Performance Research Centre New Zealand, Auckland University of Technology, Auckland, New Zealand

${ }^{4}$ Cluster for Health Improvement, Faculty of Science, Health, Education and Engineering, University of the Sunshine Coast, Sunshine Coast, Australia

${ }^{5}$ Kasturba Medical College, Mangalore, Manipal Academy of Higher Education, Manipal, Karnataka, India

${ }^{6}$ Center for Faculty Development, Kyoto University of Advanced Science, Kyoto, Japan

${ }^{7}$ School of Health and Sport Sciences, Chukyo University, Aichi, Japan

${ }^{8}$ Faculty of Health and Sport Sciences, University of Tsukuba, Ibaraki, Japan

Corresponding Author:

Jun Mizushima ${ }^{1}$

1-1-1 Tennodai, Tsukuba, Ibaraki, 305-8574, Japan

Email address: $\underline{\text { d50h60@gmail.com }}$

Acknowledgement:

We would like to thank the participants and the teachers who helped to collect the data. 


\title{
Long-term Effects of School Barefoot Running Program on Sprinting Biomechanics in Children: a Case-Control Study
}

\begin{abstract}
Background: The acute changes of running biomechanics in habitually shod children when running barefoot have been demonstrated. However, the long-term effects of barefoot running on sprinting biomechanics in children is not well understood.

Research question: How does four years of participation in a daily school barefoot running program influence sprint biomechanics and stretch-shortening cycle jump ability in children? Methods: One hundred and one children from barefoot education school (age, $11.2 \pm 0.7$ yearsold) and 93 children from a control school (age, $11.1 \pm 0.7$ years-old) performed $50 \mathrm{~m}$ maximal shod and barefoot sprints and counter movement jump and five repeated-rebound jumping. To analyse sprint kinematics, a high-speed camera (240 fps) was used. In addition, foot strike patterns were evaluated by using three high-speed cameras (300 fps). Jump heights for both jump types and the contact times for the rebound jump were measured using a contact mat system. Two-way mixed ANOVA was used to examine the effect of school factor (barefoot education school vs control school) and footwear factor (barefoot vs shod) on the sprinting biomechanics. Results: Sprinting biomechanics in barefoot education school children was characterised by significantly shorter contact times $(p=0.003)$ and longer flight times $(p=0.005)$ compared to control school children regardless of footwear condition. In shod sprinting, a greater proportion of barefoot education school children sprinted with a fore-foot or mid-foot strike compared to control school children $(\mathrm{p}<0.001)$. Barefoot education school children also had a significantly
\end{abstract}


higher rebound jump height $(\mathrm{p}=0.002)$ and shorter contact time than control school children $(\mathrm{p}$ $=0.001)$.

Significance: The results suggest that school-based barefoot running programs may improve aspects of sprint biomechanics and develop the fast stretch-shortening cycle ability in children. In order to confirm this viewpoint, adequately powered randomised controlled trials should be conducted.

Key words: barefoot; children; foot strike pattern; sprinting

\section{Introduction}

Running, in particular sprinting is a fundamental high-intensity human movement that is important in the motor development of children. Sprinting is also a motor skill that is required for high level performance in a range of recreational, sporting and occupational activities. Children are believed to develop motor skills as a result of the interactions between the neuromuscular system and environment influenced by multiple internal and external factors [19]. Footwear choice is one of the external factors which have potential to affect human running biomechanics, as the plantar surface of the foot is the only part of the body to encounter the ground during bipedal locomotion $[9,28]$.

Multiple studies have identified acute changes in running biomechanics in habitually shod children when running barefoot, such as having a higher step frequency, shorter step length and shorter contact times, and shifting their foot strike pattern from a rear-foot strike (RFS) towards mid-foot strike (MFS) or fore-foot strike (FFS) [11, 15, 16, 21]. These biomechanical alterations, especially the use of a more anterior foot strike pattern may lead to chronic changes in sprint technique $[16,21]$ and fast stretch-shortening cycle (SSC) performance as required in 
sprinting and jumping [21]. Barefoot running programs of 8 to 12 weeks duration may alter average vertical ground reaction forces, loading rates and stiffness characteristics of the lower limb during running, with less research investigating whether these changes are also found while jumping $[10,30]$. Further, only limited knowledge exists for the influence of habitual barefoot running on running and jumping biomechanics in children $[8,17,25,32]$. Another limitation of the literature for children is that the majority of the previous studies have utilised submaximal running speeds, with the only one study that investigated sprinting biomechanics focused on foot strike patterns [8].

Therefore, the primary aim of this case-control study was to compare sprinting biomechanics in children who have grown up in the same region but who differ with respect to their experience of barefoot running. We examined spatio-temporal variables, foot strike patterns and SSC jump ability to provide greater insight into the potential mechanisms underlying any of the differences in sprinting performance observed between the two groups.

\section{Methods}

\subsection{Study design}

A case-control study design was used to gain some insight into potential differences of sprint biomechanics in children who attended a barefoot education school (BS group) compared to a control school (CS group) in the same city of Japan. The barefoot education school was selected as they have provided a unique daily school physical activity program involved barefoot running for 10 minutes at their chosen speed on the surface of a hard dirt outdoors track every morning of every school day. The control school was selected as the physical activity program they offer was identical to the barefoot education school in the same city, with the exception that the 
children completed these activities while wearing shoes. The Ethics Committee of the Faculty of Health and Sports Sciences at the University of Tsukuba approved this study (IRB ID: 30-110).

\subsection{Participants}

Inclusion criteria that potential participants needed to meet included: 1) aged between 10 to 12 years; and 2) participation in the BS or CS running program for a minimum period of 4 years. Individuals who had any lower extremity injuries or illnesses on the testing dates that may influence sprinting performance were ineligible to participate. Of the 203 eligible children attending the BS or CS, 101 children of BS group (54\% boys and $46 \%$ girls; age, $11.2 \pm 0.7$ years-old; height, $1.45 \pm 0.06 \mathrm{~m}$; weight, $37.0 \pm 6.9 \mathrm{~kg}$; shoe mass, $0.19 \pm 0.03 \mathrm{~kg}$ ) and 93 children of CS group (52\% boys, $48 \%$ girls; age, $11.1 \pm 0.7$ years-old; height, $1.46 \pm 0.07 \mathrm{~m}$; weight, $37.8 \pm 7.2 \mathrm{~kg}$; shoe mass, $0.20 \pm 0.04 \mathrm{~kg}$ ) were included in this study (response rate 96\%). After gaining approval from each school director and their physical education teachers, written informed assent and consent were obtained from all participants and their parents respectively.

\subsection{Sprinting test}

After a 20-minute warming up that included static and dynamic stretching of the lower limb musculature, submaximal running drills and submaximal-effort $30 \mathrm{~m}$ running, the participants performed one trial of maximal-effort $50 \mathrm{~m}$ sprints from a standing position in both shod and barefoot conditions on the hard dirt outdoors track with $\sim 15$ minutes rest between each footwear condition. Running conditions were randomised for each child in order to minimise any learning or fatigue effect. In order to maintain ecological validity, the participants used their self-selected 
footwear normally sport shoes so as not to change their regular gait patterns. Performance in the sprinting test was quantified using a range of spatio-temporal variables and their foot strike patterns (explained below).

Figure 1 shows the experimental setup. To record sprint movement, a high-speed panning camera (LUMIX FZ200, Panasonic, Tokyo, Japan, frame rate - 240 fps, shutter speed - 1/1000) was placed $20 \mathrm{~m}$ from the right side of the runway at the midpoint $(25 \mathrm{~m})$ of the $50 \mathrm{~m}$ sprint. This position of the high-speed camera was selected so that its optical axis was perpendicular to the plane of movement at the $25 \mathrm{~m}$ mark. Reference markers were set on both sides of the runway at two-meter intervals between $20-30 \mathrm{~m}$ so to allow the reconstruction of 2-D coordinates of the body joints [24].

Please insert Figure 1 here

Twenty-three anatomical landmarks and centre of joints (3rd metacarpal head of hands, styloid process of ulnas, elbows, shoulders (glenohumeral joints), 1st toes, head of 5th metatarsal bones, tip of heels, ankles (talocrural joints), knees, greater trochanters, vertex, antilobium, and upper end of sternum) and the closest four reference markers on the runway (forward and backward on both sides) were manually digitised. This digitisation process was performed over two steps (from the left foot touchdown to the next touchdown of the same foot around the $25 \mathrm{~m}$ mark) at $120 \mathrm{~Hz}$ with a motion analysis system (Frame-DIAS IV, DKH Inc., Tokyo, Japan).

From the digitised data, 2-D coordinates ( $\mathrm{x}$ and $\mathrm{y}$ ) were reconstructed using a method previously used in sprint biomechanics research [24]. The typical error for digitising the coordinates ranged $0.001 \mathrm{~m}$ to $0.005 \mathrm{~m}$. The 2-D coordinates of the anatomical landmarks and 
centre of joints were smoothed with a Butterworth low-pass digital filter at optimal cut-off frequencies $(5.0-10.0 \mathrm{~Hz})$, determined by residual analysis [29]. Fourteen segments were then defined in Japanese children comprising hands, forearms, upper arms, feet, shanks, thighs, head and trunk, with their respective centres of gravity calculated using the smoothed coordinates [31]. To evaluate the test-retest intra-rater reliability of 2-D centre of gravity measurements via this method, the same researcher reassessed these positions over 10 sprints, with the coefficient of variation being below $3 \%$, a result comparable to that of the literature [20].

All of these spatio-temporal parameters were averaged across two consecutive steps at the $25 \mathrm{~m}$ mark, using previously reported techniques for sprinting studies [13, 20, 21]. Specifically, stance phase was defined as the period when either the left or right foot was in contact with the ground, and flight phase as the period when neither foot was in contact with the ground. Step frequency was defined as the reciprocal of the duration of the stance phase for one step, with step length as the horizontal distance the whole body's centre of gravity moved for each step. Sprint speed was defined as the mean horizontal velocity of the whole body's centre of gravity for one step.

In addition, foot strike patterns at the $25 \mathrm{~m}$ mark were captured from three angles using three high-speed cameras (EX-F1, CASIO, Tokyo, Japan, frame rate - 300 fps, shutter speed 1/1000) placed on rightward, forward diagonal and backward diagonal direction. All images of foot landing were captured on the hard disk drive of a MacBook Pro (Apple Inc., Cuptertino, CA, USA) and processed (QuickTime Player 7 Pro for Mac, Apple Inc., Cuptertino, CA, USA). Visually classification of foot strike patterns (Fig. 2): RFS (a landing in which the heel landed before the ball of the foot), MFS (a simultaneous landing of the heel and ball of the foot), and FFS (a landing in which the ball of the foot landed before the heel) were performed 
independently by two experienced reviewers blinded to each other's measures. The inter-rater reliability of the assessments of participants' foot strike patterns was excellent (linear weighted kappa $=0.946)$, with a third experienced reviewer used for consensus when required $[6,8,22]$

Please insert Figure 2 here

\subsection{Stretch-shortening cycle (SSC) jump tests}

After performing the sprinting test, the participants were given at least 10 minutes rest before performing two SSC jump tests i.e. counter movement jump (CMJ) and five repeated-rebound jumping (RJ), while wearing the same footwear that they used for the shod condition of the sprinting test. Prior to these jumps being performed, the participants performed a number of submaximal repetitions as a form of familiarisation with the required techniques. All jumps were performed without arm-swing, with both hands positioned on the hips throughout the tests.

These two jump tests were performed with three minutes rest between each jump modality $[4,23]$, as these jump tasks were selected as appropriate field-based measures to provide some insight into the potential between-group differences in sprint biomechanics [4, 27]. These jump tests were easy to perform, and useful to assess the force-power-velocity characteristics of the lower limb as RJ requires a fast SSC with a greater involvement of planter flexor muscle compared to slow SSC for the CMJ $[1,4]$.

The jump heights for both jump types and the contact time for the RJ were measured using a contact mat system (Multi Jump Tester; DKH Co., Tokyo, Japan), using standard procedures $[14,18]$. This electronic switch mat system read the ON and OFF signals during foot contact on the ground and the flight of the body in milliseconds, with this demonstrated to have 
high levels of validity and reliability in the assessment of contact times, flight times and jump height $[14,18]$. Jump height was calculated based on the acquired flight time using the following equation [2].

Jump height $(\mathrm{m})=\left(9.81 \mathrm{~m} / \mathrm{s}^{2} \times\right.$ flight time $\left.\mathrm{e}^{2}\right) \div 8$

The CMJ requested to the participants to perform two trials of one repetition with one minute of rest between jumps, and the trial with the highest jump height used for the statistical analysis. During the CMJ, the participants were instructed to jump as high as possible and land in the same position as they were at takeoff. The RJ required the participants to perform one set of five repeated jumps, whereby they were instructed to jump as high as possible and push against the ground as quickly as possible. The jump with the highest reactive strength index (RSI); i.e., the ratio of the jump height (m) divided by the contact time (s) [3, 4, 18, 23], excluding the first and last jumps, was chosen for statistical analysis. We conducted a pilot study to assess the test-retest intra-rater reliability of the jump tests among 22 children with a mean age of 11 years and the intraclass correlation coefficients for the jump test variables ranged from 0.932 to 0.965 .

\subsection{Statistical analysis}

Results were presented as mean \pm standard deviation (SD) as the assumptions of normality were met according to the results of Shapiro Wilk test. Two-way mixed ANOVA was used as the primary statistical test to examine the effect of between participants factor of group (BS group and CS group) and within participants factor of footwear condition (shod condition and barefoot condition). The Bonferroni post hoc test was undertaken for any interaction effects. McNemar's 
test was used to examine the difference in foot strike patterns between shod and barefoot conditions for each group, and Chi-square test was used to examine the difference in foot strike patterns between BS group and CS group for each condition. An independent sample t-test was used to examine the difference in physical characteristics, shoe mass and SSC ability between BS group and CS group, with 95\% confidence intervals (CI) reported. All statistical procedures were conducted using the statistical package SPSS for Mac version 25 (SPSS Inc., USA) with statistical significance set at $\mathrm{p}<0.05$.

\section{Results}

3.1. Physical characteristics and shoe mass

Table 1 demonstrates physical characteristics and shoe mass for the entire sample. There was no significant difference in age $(p=0.635)$, height $(p=0.258)$, body mass $(p=0.473)$ and shoe mass $(p=0.346)$ between BS and CS groups.

Please insert Table 1 here

\subsection{Spatio-temporal variables}

Table 2 demonstrates spatio-temporal variables for the entire sample. There was a significant interaction between group and footwear condition for sprint speed $(p<0.001)$ and step length ( $p$ $<0.001)$. Sprint speed in the BS group was significantly higher in the barefoot than in shod condition $(\mathrm{p}<0.001)$ and sprint speed in the barefoot condition was significantly higher in the BS than in CS group $(p=0.015)$. Post hoc tests showed that the CS group's step length was 
significantly shorter in the barefoot than in shod condition $(\mathrm{p}<0.001)$ and step length in the barefoot condition was significantly longer for the BS than in CS group $(\mathrm{p}=0.032)$.

There were significant main effects of group on contact times $(p=0.003)$ and flight times $(p=0.005)$, with significantly shorter contact times and longer flight times in the BS than in CS group. There were significant main effects of footwear condition on step frequency $(p<0.001)$ and contact times $(\mathrm{p}<0.001)$, with significantly higher step frequency and shorter contact times in the barefoot than shod condition.

Please insert Table 2 here

\subsection{Foot strike patterns}

Table 3 demonstrates a summary of the foot strike patterns. Chi-square test indicated there was a significant effect of group on foot strike patterns in the shod condition $\left(X^{2}(2, N=194)=\right.$ $16.108, \mathrm{p}<0.001$ ) with a lower percentage of RFS in the BS than CS group. In contrast, no significant differences were found in foot strike patterns for the barefoot condition $\left(\mathrm{X}^{2}(2, \mathrm{~N}=\right.$ $194)=5.088, p=0.079)$. Significant effects of footwear condition on foot strike patterns were observed, demonstrating a greater percentage of RFS in the shod condition, whereas this decreased in the barefoot condition for both BS $(\mathrm{p}<0.001)$ and CS $(\mathrm{p}<0.001)$ groups.

Please insert Table 3 here

3.4. Stretch-shortening-cycle jump ability 
Table 4 demonstrates SSC jump ability for the entire sample. RJ height was significantly greater $(p=0.002)$, contact times significantly shorter $(p=0.001)$ and RSI significantly higher $(p<$ 0.001) in the BS than CS group. No significant differences in CMJ height were found between BS and CS groups $(p=0.492)$.

Please insert Table 4 here

\section{Discussion}

The major finding of this study was that characteristics of sprinting biomechanics and fast SSC ability differ between children who have grown up in the same region but who differ with respect to their experience of barefoot running. Children in the BS group, who completed 10 minutes of barefoot running every school day for a minimum of four years, were observed to sprint with a shorter contact time and longer flight time and a use a more anterior foot strike pattern, while also having greater fast SSC ability than children in the CS group.

A higher probability of a RFS pattern in habitually barefoot than shod children in both shod and barefoot conditions has been reported at what was defined as maximal running speeds $(3.70-3.98 \mathrm{~m} / \mathrm{s})$ [8]. On the contrary, our results showed that the BS group tended to have a reduced probability of a RFS for the shod and no difference in their foot strike patterns for the barefoot condition. There are several possible explanations for these between-study differences in foot strike patterns. Although both Hollander et al. [8] and the current study asked their participants to run or sprint maximally, sprint speed was relatively slower in habitually barefoot children examined [8] compared to the BS group in the current study (6.09 compared to 6.33 $\mathrm{m} / \mathrm{s}$ ), whereby foot strike pattern can be altered at running speed above $5 \mathrm{~m} / \mathrm{s}$ in adult runners 
[5]. Furthermore, the between-study differences in sprint speed might be due to differences in the age of the participants (mean age of 12.1 years ranging from 6 to 18 years in Hollander et al [8] compared to mean age of 11.2 years ranging from 10 to 12 years in the current study). Another factor to consider is the difference of habituation level between both studies. Hollander et al. [8] investigated habitually barefoot children from South Africa who spend approximately one half of their time barefoot at school and during sports, while also being barefoot at home based on the result of a barefoot questionnaire [12]. Although the BS group in the current study had participated in a school barefoot running program for 10 minutes every school day for a minimum of four years (around 130 hours in total), this is obviously substantially less than what would have been achieved by the South African children [8]. Nevertheless, significant changes in foot strike patterns have been observed in training studies lasting only 8 to 12 weeks that would have likely involved less than the minimum of 130 hours of barefoot running performed in the current study $[10,30]$. Therefore, what constitutes the minimal dosage of barefoot running required to produce significant changes in sprinting biomechanical characteristics including foot strike patterns, spatio-temporal parameters and overall SSC ability still remains somewhat unclear.

Regardless of these similarities and differences in the results of the present study and that of Hollander et al. [8], the differences observed in both groups of children sprinting shod compared to barefoot were similar to that reported in the literature. Specifically, when sprinting barefoot compared to shod, there was a relative shift from RFS to MFS or FFS, a shorter contact time and a higher step frequency in the BS and CS groups. These results are consistent with those previously reported by Mizushima et al. [21] in 94 habitually shod children at sprinting speeds $(5.48-5.60 \mathrm{~m} / \mathrm{s})$. However, the results of the current study indicated that the BS group 
could run faster in barefoot condition compared to the shod condition, while still maintaining their step length. It was also observed that the CS group was significantly slower than the BS group when running barefoot, with this perhaps a result of the CS group's reduced step length when running barefoot.

The greater running speed of the BS group during the barefoot condition may be explained by the impulse-momentum relationship. Specifically, the impulse-momentum relationship states that an impulse (force multiplied by time) is required to produce a change in momentum (mass multiplied by velocity) of the system. As the BS group achieved similar or greater sprinting speeds with shorter contact times than the CS group, the BS group's impulse would have to be characterised by a larger ground reaction force and/or had a greater rate of force development than the CS group during ground contact. This assumption that long-term participation in the school barefoot running program for the BS group may have made them more efficient in transmitting and/or receiving force toward/from the ground in barefoot sprinting could be reflective of a series of adaptations in SSC ability and/or the musculoskeletal system [10]. Such a view is consistent with our findings whereby the BS group had a significantly higher RJ height, RSI and shorter contact time than the CS group, although no significant difference in CMJ height was observed. As the RJ requires a fast SSC compared to slow SSC for the CMJ $[1,4]$, the school-based barefoot running program might have selectively contributed to the improvements in the BS children's fast SSC ability. Considering that children often utilise a MFS or FFS landing when running barefoot, it could suggest barefoot running for extended periods of time may act as a stimulus to improve fast SSC performance as it enhances the force-power-velocity characteristics of the lower limb (especially plantar flexor muscles) $[1$, 4]. 
Based on our results and the emerging literature, physical education teachers or sports coaches may wish to include some proportion of barefoot running in every physical education class and sporting programs in children to improve a fast SSC ability. It is also known that such habitual barefoot running can contribute to a range of morphological adaptations in the foot characteristics such as foot arch, hallux angles and foot pliability [7], perhaps as a result of the greater loading of these structures $[10,26]$. Future research would need to confirm the minimum/optimal dosage of barefoot running to improve sprinting and SSC ability and/or to produce beneficial morphological adaptations in children of different ages and activity levels and how this can be progressed.

There were still a number of limitations to the study's design. As each child used their own footwear in the shod condition, results for the shod condition may have been affected by between-participant differences in footwear properties such as cushioning, flexibility and heelto-toe drop between the groups. Moreover, we didn't use a barefoot running questionnaire [12] to determine habituation level of the participants in this study. Further, timing lights were not available to assess sprinting time over the entire $50 \mathrm{~m}$ course.

\section{Conclusion}

In conclusion, the results of this study demonstrate the long-term effects of participation in a school-based barefoot running program on children's sprinting biomechanics and jumping ability. Specifically, the BS group adopted a more anterior foot strike patterns and had a greater fast stretch-shortening cycle ability, as indicated by their reduced ground contact times and faster running speeds in the barefoot sprinting condition and their greater RJ performance. There is clearly a need to better understand the positive chronic adaptation and potential risks of habitual 
barefoot running and sprinting in children and to quantify how best to begin and progress

barefoot running in this population. Longitudinal research involving cohort or randomised

controlled trial designs would be useful to provide more information about the potential positive

outcomes and injury risk of barefoot running and how best to progress this in children of

different ages and levels of physical activity.

\section{Declaration of Conflicting Interests}

The author(s) declared no potential conflicts of interest with respect to the research, authorship, and/or publication of this article.

\section{Reference}

[1] Bobbert MF, Mackay M, Schinkelshoek D, Huijing PA, van lngen Schenau GJ, Biomechanical analysis of drop and countermovement jumps. Eur. J. Appl. Physiol. Occup. Physiol., 54 (1986) 566-573. https://doi.org/10.1007/BF00943342.

[2] Bosco C, Luhtanen P, Komi PV, A simple method for measurement of mechanical power in jumping. Eur. J. Appl. Physiol. Occup. Physiol., 50 (1983) 273-282. https://doi.org/10.1007/BF00422166.

[3] Douglas J, Pearson S, Ross A, McGuigan M, Kinetic Determinants of Reactive Strength in Highly Trained Sprint Athletes. J. Strength Cond. Res., 32 (2018) 1562-1570. http://doi.org/10.1519/JSC.0000000000002245.

[4] Endo T, Tauchi K, Ogata M, Development of running and footwork abilities from a viewpoint of jumping ability characteristics. Int. J. Sport Health Sci., 6 (2007) 120-127.

[5] Forrester SE, Townend J, The effect of running velocity on footstrike angle-A curveclustering approach. Gait Posture, 41 (2015) 26-32. https://doi.org/10.1016/j.gaitpost.2014.08.004

[6] Hoenig T, Rolvien T, Hollander K, Foot strike patterns in runners: concepts, classifications, techniques, and implications for running-related injuries. Dtsch Z Sportmed., 71 (2020) 5561. http://doi.org/10.5960/dzsm.2020.424.

[7] Hollander K, De Villiers JE, Sehner S, Wegscheider K, Braumann KM, Venter R, Zech A, Growing-up (habitually) barefoot influences the development of foot and arch morphology in children and adolescents. Sci. rep., 7 (2017) 1-9. http://doi.org/10.1038/s41598-01707868-4.

[8] Hollander K, de Villiers JE, Venter R, Sehner S, Wegscheider K, Braumann KM, Zech A, Foot Strike Patterns Differ Between Children and Adolescents Growing up Barefoot vs. Shod. Int. J. Sports Med., 39 (2018) 97-103. http://doi.org/10.1055/s-0043-120344. 
[9] Hollander K, Heidt C, Van Der Zwaard BC, Braumann KM, Zech A, Long-term effects of habitual barefoot running and walking: a systematic review. Med. Sci. Sports Exerc., 49 (2017) 752-762. http://doi.org/10.1249/MSS.0000000000001141.

[10] Hollander K, Liebl D, Meining S, Mattes K, Willwacher S, Zech A, Adaptation of running biomechanics to repeated barefoot running: a randomized controlled study. Am. J. Sport. Med., 47 (2019) 1975-1983. https://doi.org/10.1177/0363546519849920.

[11] Hollander K, Riebe D, Campe S, Braumann KM, Zech A, Effect of footwear on treadmill running biomechanics in preadolescent. Gait Posture, 40 (2014) 381-385. http://doi.org/10.1016/i.gaitpost.2014.05.006.

[12] Hollander K, van der Zwaard BC, de Villiers JE, Braumann KM, Venter R, Zech A, The effects of being habitually barefoot on foot mechanics and motor performance in children and adolescents aged 6-18 years: Study protocol for a multicenter cross-sectional study (Barefoot LIFE project). J. Foot Ankle Res. (2016) 9-36. http://doi.org/10.1186/s13047016-0166-1.

[13] Hunter JP, Marshall RN, McNair P, Reliability of biomechanical variables of sprint running. Med. Sci. Sports Exerc., 36 (2004) 850-861. http://doi.org/10.1249/01.mss.0000126467.58091.38.

[14] Kenny IC, Cairealláin AÓ, Comyns TM, Validation of an Electronic Jump Mat to Assess Stretch-Shortening Cycle Function. J. Strength Cond. Res., 26 (2012) 1601-1608. http://doi.org/10.1519/JSC.0b013e318234ebb8.

[15] Latorre-Román PÁ, Balboa FR, García-Pinillos F, Foot strike pattern in children during shod-unshod running. Gait Posture, 58 (2017) 220-222. http://doi.org/10.1016/i.gaitpost.2017.07.121.

[16] Latorre-Román PÁ, Párraga-Montilla JA, Guardia-Monteagudo I, and García-Pinillos F, Foot strike pattern in preschool children during running: sex and shod-unshod differences. Eur. J. Sport Sci., 18 (2018) 1-8. http://doi.org/10.1080/17461391.2017.1422545.

[17] Lieberman DE, Venkadesan M, Werbel WA, Daoud AI, D'Andrea S, Davis IS, Mang'Eni RO, Pitsiladis Y, Foot strike patterns and collision forces in habitually barefoot versus shod runners. Nature, 463 (2010) 531-535. http://doi.org/10.1038/nature08723.

[18] Lloyd RS, Oliver JL, Hughes MG, Williams CA, Reliability and validity of field-based measures of leg stiffness and reactive strength index in youths. J. Sports Sci., 27 (2009) 1565-1573. http://doi.org/10.1080/02640410903311572.

[19] Malina RM, Bouchard C, Bar-Or O, Growth, maturation, and physical activity. Champaign, IL: Human Kinetics, 2004.

[20] Miyamoto A, Takeshita T, Yanagiya T, Differences in sprinting performance and kinematics between preadolescent boys who are fore/mid and rear foot strikers. PLoS One, 13 (2018) e 0205906. https://doi.org/10.1371/journal.pone.0205906.

[21] Mizushima J, Seki K, Keogh JWL, Maeda K, Shibata A, Koyama H, Ohyama-Byun K, Kinematic characteristics of barefoot sprinting in habitually shod children. PeerJ, 6 (2018) e5188. https://doi.org/10.7717/peerj.5188.

[22] Murray L, Beaven CM, Hébert-Losier K, Reliability of Overground Running Measures from 2D Video Analyses in a Field Environment. Sports (Basel), 7 (2018) 8. https://doi.org/10.3390/sports7010008.

[23] Nagahara R, Naito H, Miyashiro K, Morin JB, Zushi K, Traditional and ankle-specific vertical jump as strength-power indicators for maximal sprint acceleration. J. Sports Med. Phys. Fitness, 54 (2014) 691-699. 
[24] Nagahara R, Naito H, Morin JB, Zushi K, Association of acceleration with spatiotemporal variables in maximal sprinting. Int. J. Sports Med., 35 (2014) 755-761. http://doi.org/10.1055/s-0033-1363252.

[25] Pontzer H, Suchman K, Raichlen DA, Wood BM, Mabulla AZP, Marlowe FW, Foot strike patterns and hind limb joint angles during running in Hadza hunter-gatherers. J. Sport Health Sci., 3 (2014) 95-101. https://doi.org/10.1016/j.jshs.2014.03.010.

[26] Smith G, Lake M, Lees A, Metatarsophalangeal joint function during sprinting: a comparison of barefoot and sprint spike shod foot conditions. J. Appl. Biomech., 30 (2014) 206-212. http://doi.org/10.1123/jab.2013-0072.

[27] Swinton PA, Lloyd R, Keogh JW, Agouris I, Stewart AD, Regression models of sprint, vertical jump, and change of direction performance. J. Strength. Cond. Res., 28 (2014) 1839-1848. http://doi.org/10.1519/JSC.0000000000000348.

[28] Wegener C, Hunt AE, Vanwanseele B, Burns J, Smith RM, Effect of children's shoes on gait: A systematic review and meta-analysis. J. Foot Ankle Res., 4 (2011) 3. http://doi.org/10.1186/1757-1146-4-3.

[29] Wells RP, Winter DA, Assesment of signal and noise in the kinematics normal, pathological and sporting gaits. Human Locomotion I (1980) 92-93.

[30] Yang Y, Zhang X, Luo Z, Wang X, Ye D, Fu W, Alterations in Running Biomechanics after 12 Week Gait Retraining with Minimalist Shoes. Int. J. Environ. Res. Public Health, 17 (2020) 818. http://doi.org/10.3390/ijerph17030818.

[31] Yokoi T, Shibukawa K, Ae M, Body segment parameters of Japanese children. Japan J. Phys. Educ. Hlth. Sport Sci., 31 (1986) 53-66. https://doi.org/10.5432/ijpehss.KJ00003392242.

[32] Zech A, Venter R, de Villiers JE, Sehner S, Wegscheider K, Hollander K, Motor Skills of Children and Adolescents Are Influenced by Growing up Barefoot or Shod. Front. Pediatr., 6 (2018) 115. https://doi.org/10.3389/fped.2018.00115. 
Figure 1. Experimental setup.

Figure 2. Definitions of foot strike patterns. (A) Rear-foot strike (RFS); (B) Mid-foot strike (MFS); (C) Fore-foot strike (FFS). 


\section{Figure}

F : Foot strike

$S$ : Sprint motion

\section{$25 \mathrm{~m}$}

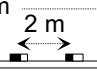

$\mathrm{F}$

$1 \mathrm{~m}$

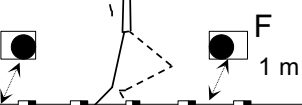

$1.25 \mathrm{~m}$

.
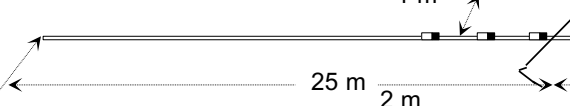

$25 \mathrm{~m}$

AS
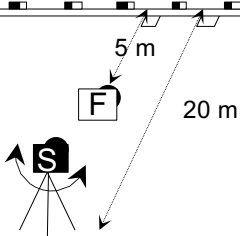


\section{Figure}

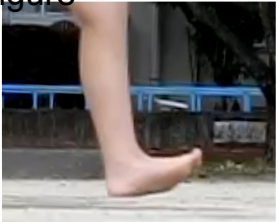

(A) Rear-foot strike (RFS)

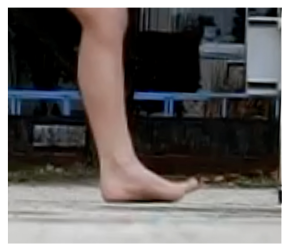

(B) Mid-foot strike (MFS)

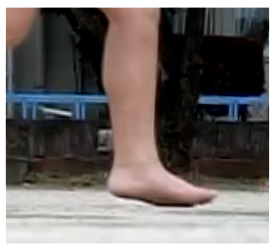

(C) Fore-foot strike (FFS) 
Table 1. A summary of the physical characteristics and shoe mass for both groups.

\begin{tabular}{|l|l|l|l|l|}
\hline & BS group & CS group & t-value & $95 \% \mathrm{CI}$ \\
\hline Age (years) & $11.2 \pm 0.7$ & $11.1 \pm 0.7$ & -1.135 & -0.155 to 0.253 \\
\hline Height $(\mathrm{m})$ & $1.45 \pm 0.06$ & $1.46 \pm 0.07$ & -0.719 & -3.086 to 0.831 \\
\hline Body mass $(\mathrm{kg})$ & $37.1 \pm 6.9$ & $37.8 \pm 7.2$ & 0.476 & -2.716 to 1.265 \\
\hline Shoes mass $(\mathrm{kg})$ & $0.19 \pm 0.03$ & $0.20 \pm 0.04$ & -0.945 & -0.015 to 0.005 \\
\hline
\end{tabular}

CI: Confidence interval

BS group: Children from barefoot education school, CS group: Children from control school 
Table 2. A summary of the key spatiotemporal variables for both groups across both footwear conditions.

\begin{tabular}{|c|c|c|c|c|}
\hline & & Shod condition & Barefoot condition & F-value \\
\hline \multirow[t]{3}{*}{ Sprint velocity $(\mathrm{m} / \mathrm{s})$} & BS group & $6.09 \pm 0.60$ & $6.33 \pm 0.56^{\dagger+*}$ & $\mathrm{Fa}=18.205^{* *}$ \\
\hline & CS group & $6.14 \pm 0.55$ & $6.14 \pm 0.57$ & $\mathrm{Fb}=0.950$ \\
\hline & & & & $\mathrm{Fc}=21.449 * *$ \\
\hline \multirow[t]{3}{*}{ Step frequency $(\mathrm{Hz})$} & BS group & $3.91 \pm 0.30$ & $4.10 \pm 0.30$ & $\mathrm{Fa}=115.925^{* *}$ \\
\hline & CS group & $3.91 \pm 0.30$ & $4.08 \pm 0.32$ & $\mathrm{Fb}=0.068$ \\
\hline & & & & $\mathrm{Fc}=0.402$ \\
\hline \multirow[t]{2}{*}{ Step length (m) } & BS group & $1.56 \pm 0.14$ & $1.55 \pm 0.12^{\sharp}$ & $\mathrm{Fa}=26.924 * *$ \\
\hline & CS group & $1.57 \pm 0.12^{\dagger \dagger}$ & $1.51 \pm 0.14$ & $\mathrm{Fb}=0.634$ \\
\hline
\end{tabular}




\begin{tabular}{|l|l|l|l|l|}
\hline & & & & $\mathrm{Fc}=12.802^{* *}$ \\
\hline \multirow{2}{*}{ Contact time (s) } & BS group & $0.138 \pm 0.017$ & $0.128 \pm 0.015$ & $\mathrm{Fa}=181.564^{* *}$ \\
\cline { 2 - 6 } & CS group & $0.143 \pm 0.017$ & $0.133 \pm 0.015$ & $\mathrm{Fb}=6.201^{* *}$ \\
\cline { 2 - 6 } & & & & $\mathrm{Fc}=0.059$ \\
\hline \multirow{2}{*}{ Flight time (s) } & BS group & $0.119 \pm 0.013$ & $0.117 \pm 0.012$ & $\mathrm{Fa}=0.607$ \\
\cline { 2 - 6 } & CS group & $0.113 \pm 0.014$ & $0.113 \pm 0.014$ & $\mathrm{Fb}=7.972 * *$ \\
\cline { 2 - 6 } & & & & $\mathrm{Fc}=0.928$ \\
\hline
\end{tabular}

Fa: Main effect of footwear condition, Fb: Main effect of group, Fc: Interaction effect, **: $p<0.01$

Shoes condition vs Barefoot condition, ${ }^{\dagger}: \mathrm{p}<0.01$ 
BS group vs CS group, ${ }^{+}$p $<0.05$

BS group: Children from barefoot education school, CS group: Children from control school 
Table 3. A summary of the foot strike pattern for both groups across both conditions.

\begin{tabular}{|l|l|l|l|l|}
\hline & & \multicolumn{3}{|l|}{ Foot strike pattern (\%) } \\
\hline & & RFS & MFS & FFS \\
\hline BS group & Shod condition & 57.4 & 30.7 & 11.9 \\
\hline & Barefoot condition & 23.8 & 38.6 & $37.6^{* *}$ \\
\hline CS group & Shod condition & $81.7^{\dagger \dagger}$ & 8.6 & 9.7 \\
\hline & Barefoot condition & 34.4 & 41.9 & $23.7^{* *}$ \\
\hline
\end{tabular}

Main effect of footwear condition, $* *: p<0.01$

Main effect of group, ${ }^{\dagger \dagger}: \mathrm{p}<0.01$ 
BS group: Children from barefoot education school, CS group: Children from control school

RFS: Rear-foot strike, MFS: Mid-foot strike, FFS: Fore-foot strike 
Table 4. A summary of the stretch-shortening cycle exercise (SSC) ability for both groups.

\begin{tabular}{|l|l|l|l|l|}
\hline & BS group & CS group & t-value & $95 \%$ CI \\
\hline RJ RSI & $1.31 \pm 0.36^{* *}$ & $1.13 \pm 0.34$ & 3.775 & 0.090 to 0.287 \\
\hline RJ height (m) & $0.23 \pm 0.04^{* *}$ & $0.21 \pm 0.04$ & 3.077 & 0.006 to 0.028 \\
\hline RJ contact time (s) & $0.178 \pm 0.028^{* *}$ & $0.192 \pm 0.031$ & -3.377 & -0.022 to -0.060 \\
\hline CMJ height (m) & $0.25 \pm 0.04$ & $0.24 \pm 0.04$ & 0.689 & -0.076 to 0.016 \\
\hline
\end{tabular}

$* *: \mathrm{p}<0.01$ 
CI: Confidence interval

BS group: Children from barefoot education school, CS group: Children from control school

RJ: Five repeated-rebound jumping, RSI: Reactive strength index, CMJ: Counter movement jump 